treatments (prednisolone or tetracosactide depot) than following vigabatrin (Lux AL et al. Lancet 2004;364:1773-1776). At 4-year follow-up, 9 of 107 enrolled infants had died and 77 were tested for level of development, using the Vineland Adaptive Behavior Scales (VABS), and for seizure control by questionnaire. The median VABS scores were 60 for 39 children allocated hormonal treatment and 50 for 38 allocated vigabatrin $(\mathrm{p}=0.91)$. For children with spasms with no identified etiology, VABS scores were 96 for 21 allocated hormonal treatment, and 63 for the 16 allocated vigabatrin $(\mathrm{p}=0.033)$. For all 77 infants, development and epilepsy outcomes were not significantly different between the two treatment groups at 4-year follow-up. In patients with no identifiable etiology, development was better at both 14 months and 4 years in those allocated hormonal treatment. (Darke K, Edwards SW, Hancock E, et al. Developmental and epilepsy outcomes at age 4 years in the UKISS trial comparing hormonal treatments to vigabatrin for infantile spasms: a multi-centre randomized trial. Arch Dis Child May 2010;95:382386). (Respond: Dr Finbar O'Callaghan, Bristol Royal Hospital for Children. Upper Maudlin St, Bristol BS2 8BJ, UK; E-mail: finbar.ocallaghan@bristol.ac.uk).

COMMENT. A review of the earlier report of the UKISS with a primary outcome of cessation of spasms on days 13 and 14 (Lux et al. Lancet 2004;364:1773-8) found the minimum doses used were vigabatrin $100 \mathrm{mg} / \mathrm{kg} /$ daily $(\mathrm{n}=52)$, oral prednisolone $40 \mathrm{mg}$ day $(n=30)$ or intramuscular tetracosactide depot $0.5 \mathrm{mg}(40 \mathrm{IU})(\mathrm{n}=25)$ on alternate days. Complete seizure control was obtained in $40(73 \%)$ on hormonal treatments (prednisolone $21(70 \%)$, tetracosactide $19(76 \%)$ ) and $28(54 \%)$ on vigabatrin $(\mathrm{p}=0.043)$. Adverse events were reported in $30(55 \%)$ of 55 infants on hormonal treatments and 28 $(54 \%)$ of 52 on vigabatrin. Cessation of spasms occurred more often in infants on hormonal treatment than those given vigabatrin. Adverse events were common with both treatments. The subsequent studies show that hormonal treatment and vigabatrin are equally effective in control of infantile spasms with proven etiology, but for spasms with no identifiable cause, hormonal treatment is preferred.

\title{
VITAMIN D INSUFFICIENCY IN CHILDREN WITH EPILEPSY
}

Prevalence and risk factors for vitamin D insufficiency among 78 children with epilepsy, aged 3-17 years, treated September 2008-March 2009, were evaluated in a study at the University of Michigan, Ann Arbor, MI. Sex ratio M:F was 41:59; 81\% of European origin; mean age 11.64 years. Low levels of 25 -hydroxyvitamin D $(<20 \mathrm{ng} / \mathrm{ml})$ were found in $25 \%$ of the children and normal levels $(>32 \mathrm{ng} / \mathrm{ml}$ ) occurred in only $25 \%$. Girls and children with elevated body mass index were at increased risk for low 25hydroxyvitamin D. Newer less potent enzyme-inducing antiepileptic drug use (lamotrigine, levetiracetam, oxcarbazepine, gabapentin, topiramate, vigabatrin, zonisamide) was not associated with altered risk compared with older enzyme-inducing drugs (carbamazepine, phenobarbital, phenytoin). The risk was higher for those with localization-related partial epilepsy but these patients had higher body mass index. (Shellhaas RA, Barks AK, Joshi SM. Prevalence and risk factors for vitamin D insufficiency among children with epilepsy. Pediatr Neurol June 2010;42:422-426). (Respond: Dr Shellhaas, L3215 Women's Hospital, 1500 E Medical Center Drive, SPC 5203, Ann Arbor, MI 48109; E-mail: shellhaa@med.umich.edu). 
COMMENT. Vitamin D insufficiency is prevalent among almost all children with epilepsy, and the risk is significantly increased for female patients and in patients with increased body mass index. Specific antiepileptic drug usage, comorbid cerebral palsy or intellectual retardation, and seizure control, potential risk factors for vitamin D insufficiency, did not contribute to the risk in this patient cohort. Patients with partial seizures were at increased risk, but the significance of this observation was confounded by the associated elevated body mass index. Prevalence of hypovitaminosis D is high in the general pediatric population, but patients with epilepsy are at additional risk for bone injury and other complications. Increased attention to vitamin D levels and more extensive use of vitamin D supplementation are warranted in children with epilepsy, especially girls and those with elevated body mass index.

In a review article on vitamin $\mathrm{D}$ and bone health in children with epilepsy (Shellhaas RA, Joshi SM. Pediatr Neurol 2010;42:385-393), the authors suggest methods for vitamin D supplementation based on 25-hydroxyvitamin D levels ( $\mathrm{ng} / \mathrm{ml}$ ), pending official guidelines. They advocate screening for vitamin D insufficiency and supplementation with cholecalciferol to maintain optimal vitamin D levels.

In an editorial, Wirrell E, Mayo Clinic, Rochester, MN, (Pediatr Neurol 2010;42:394-395) agrees with Shellhaas and Joshi that all children with epilepsy should receive $400 \mathrm{IU}$ of vitamin $\mathrm{D}$ and an optimal calcium intake and diet. Further, a dose of vitamin $\mathrm{D}$ at $1000 \mathrm{IU}$ per day should be considered for children with symptomatic generalized epilepsy, those with impaired mobility, and those treated with polytherapy. Screening for vitamin D levels should be considered for all children with epilepsy. Bone mineral density screening without pathologic fracture requires further study. Vitamin D insufficiency in pediatric epilepsy appears to be neglected, probably as a result of conflicting study findings.

\section{DEMYELINATING DISORDERS}

\section{VITAMIN D STATUS AND MULTIPLE SCLEROSIS RELAPSE}

Researchers at University of California, San Francisco, and State University of New York at Stony Brook, NY consecutively recruited patients with pediatric-onset multiple sclerosis into a prospective cohort to determine if vitamin D status is associated with the rate of subsequent clinical relapses. Among 110 patients followed, the mean serum 25-hydroxyvitamin D level was $22+/-9 \mathrm{ng} / \mathrm{ml}$, and only $16(15 \%)$ had normal unadjusted levels (>30 ng/ml). After adjustment for age, gender, race, ethnicity, disease duration, therapy, and length of follow-up, every $10 \mathrm{ng} / \mathrm{ml}$ increase in adjusted 25hydroxyvitamin D level was associated with a $34 \%$ decrease in the rate of subsequent relapses $(\mathrm{p}=0.024)$. Only Hispanic ethnicity was independently associated with an increased risk of relapse. The finding suggests that supplementation of vitamin D stores may reduce risk of multiple sclerosis relapse and warrants investigation. (Mowry EM, Krupp LB, Milazzo M et al. Vitamin D status is associated with relapse rate in pediatriconset multiple sclerosis. Ann Neurol May 2010;67:618-624). (Respond: Dr Mowry, Department of Neurology, Multiple Sclerosis Center, University of California, San 